\title{
Microstructure and interaction among Ce-As-Fe at high temperature
}

\author{
Weiyu Yang ${ }^{\mathrm{a}}$, Jinzhu Zhang ${ }^{\mathrm{b}}$, Shuie $\mathrm{Li}^{\mathrm{c}}$ \\ College of Materials and Metallurgy, Guizhou University, Guiyang 550025, China \\ a 404333078@qq.com, b zjz-yjx@163.com, ${ }^{c}$ longlong9812@163.com \\ Corresponding author E-mail address: zjz-yjx@163.com
}

\section{Keywords: temperature; Arsenic; compound}

Abstract: In this study, a certain amount of rare earth metal Cerium and low melting point Arsenic were closed in the barrel-shaped cylinder machined by $\mathrm{H} 08$ steel, heated to $1223 \mathrm{~K}, 1273 \mathrm{~K}$ and $1323 \mathrm{~K}$ respectively for $50 \mathrm{~h}$, and the interaction among the cerium, arsenic and iron was studied by X-ray diffraction, optical microscopy, and electronic probe microscopy analysis. The result shows that the ternary compound $\mathrm{Ce}_{12} \mathrm{Fe}_{57.5} \mathrm{As}_{41}$ is one of the main interaction product at high temperature in $\mathrm{Ce}-\mathrm{As}-\mathrm{Fe}$ system when the atomic ratio of Cerium to Arsenic is 1:3. The chemical stability of the compound $\mathrm{Ce}_{12} \mathrm{Fe}_{57.5} \mathrm{As}_{41}$ decreases with the temperature raising between $1223 \mathrm{~K}$ and $1323 \mathrm{~K}$.

\section{Introduction}

Arsenic in steel mainly segregated on grain boundary and it is probably that the impact toughness, the cold brittleness and the hot-working performance of steel would be deteriorated ${ }^{[1-4]}$. The Arsenic in steel commonly come from a certain amount of iron ores but it is difficult to removal in the conventional ironmaking and steelmaking process because its oxidation potential is lower than that of Iron. The rare earth metals, which have a stronger affinity with the deleterious impurities such as oxygen, sulfur, phosphorus and some low melting point metals contained in steel, are often used to purify the liquid steel ${ }^{[5]}$. According to the thermodynamic property in binary phase diagram, the compounds $\mathrm{CeAs}, \mathrm{Ce}_{4} \mathrm{As}_{3}$ and $\mathrm{CeAs}_{2}$ can be developed in Cerium Arsenic system ${ }^{[6]}$. With a higher content of Cerium in steel, the compounds $\mathrm{Fe}_{2} \mathrm{Ce}$ and $\mathrm{Fe}_{17} \mathrm{Ce}_{2}$ can be developed by heating the cerium and iron at $1180^{\circ} \mathrm{C}$ for 30 hours, and slowly cooling to $900^{\circ} \mathrm{C}$, then annealing ${ }^{[6]}$. Moreover, it was reported if the Ce pieces, Fe powder, and As lumps in a molar ratio of 1:5:3 was placed in an evacuated fused-silica tube together with a 6-fold (by weight) excess of Sn, stepwise heated to $900^{\circ} \mathrm{C}$ over 3 days, held at this temperature for 4 days, and slowly cooled $\left(4^{\circ} \mathrm{C} / \mathrm{h}\right)$ to $600^{\circ} \mathrm{C}$, the ternary arsenide $\mathrm{RE}_{12} \mathrm{Fe}_{57.5} \mathrm{As}_{41}$ and $\mathrm{FeAs}$ were obtained ${ }^{[7]}$. In this study, a certain amount of rare earth metal Cerium and low melting point Arsenic were closed in the barrel-shaped cylinder machined by $\mathrm{H} 08$ steel, heated to $1223 \mathrm{~K}, 1273 \mathrm{~K}$ and $1323 \mathrm{~K}$ respectively for $50 \mathrm{~h}$, and the interaction among the cerium and arsenic in steel was studied by X-ray diffraction, optical microscopy, and electronic probe microscopy analysis.

\section{Experiment}

The sample preparation device like a pressure-tight cylinder is shown in figure 1, and machined by $\mathrm{H} 08$ steel of which the main composition is as follows: $0.35 \%$ (mass percent) Manganese, 0.03\% Silicon, $0.082 \%$ Carbon, $0.016 \%$ Phosphorus, $0.014 \%$ Sulphur, and 99.3\% Iron. The metal 
Cerium pieces (purity 99.0\%) and the non-metal Arsenic particle (purity 99.99\%) with a size below $5 \mathrm{~mm}$ are weight $3.835 \mathrm{~g}$ and $6.164 \mathrm{~g}$ respectively with an atomic ratio of Ce to As $1: 3$, put into the cylinder, then screwed down and welded the cylinder.

The cylinder was put into SRJK-2-9-tube vacuum resistance, and heated slowly in the reduction atmosphere as $\mathrm{H}_{2}: \mathrm{Ar}=1: 10$. The temperature was controlled based on the vapor pressure of Arsenic as follows: taking $2 \mathrm{~h}$ for room temperature to $773 \mathrm{~K}$, from $773 \mathrm{~K}$ to $923 \mathrm{~K}$, taking $10 \mathrm{~min}$ for increasing every ten degrees, from $923 \mathrm{~K}$ to $983 \mathrm{~K}$, taking $20 \mathrm{~min}$ for increasing every ten degrees, from $983 \mathrm{~K}$ to $1023 \mathrm{~K}$, taking $30 \mathrm{~min}$ for increasing every ten degrees, from $1023 \mathrm{~K}$ to $1073 \mathrm{~K}$, taking $2 \mathrm{~h}$ for increasing every ten degrees, from $1073 \mathrm{~K}$ to $1123 \mathrm{~K}$, taking $4 \mathrm{~h}$ for increasing every ten degrees, from $1123 \mathrm{~K}$ to $1173 \mathrm{~K}$, taking $5 \mathrm{~h}$ for increasing every ten degrees, from $1173 \mathrm{~K}$ to $1223 \mathrm{~K}$, taking $6 \mathrm{~h}$ for increasing every ten degrees, at $1223 \mathrm{~K}$, keeping $50 \mathrm{~h}$ for sample 1; from $1223 \mathrm{~K}$ to $1273 \mathrm{~K}$, taking $7 \mathrm{~h}$ for increasing every ten degrees, at $1273 \mathrm{~K}$, keeping $50 \mathrm{~h}$ for Sample 2; from $1273 \mathrm{~K}$ to $1323 \mathrm{~K}$, taking $8 \mathrm{~h}$ for increasing every ten degrees, at $1323 \mathrm{~K}$, keeping $50 \mathrm{~h}$ for Sample 3. Then the furnace was turned off, cooled to room temperature and switched off the protective hydrogen and argon.

The sample was sawed off laterally about $16 \mathrm{~mm}$ away from the bottom by hand. One part of the samples was prepared for metallographic observation by the conventional methods. The other part was scratched, and taken the central substance that was mainly developed from Cerium, Arsenic, and Iron in the high temperature off the cylinder. Then the substance from the internal infiltration layer scratched off was crushed, ground, and used for phases or compounds determination by X-ray diffraction.
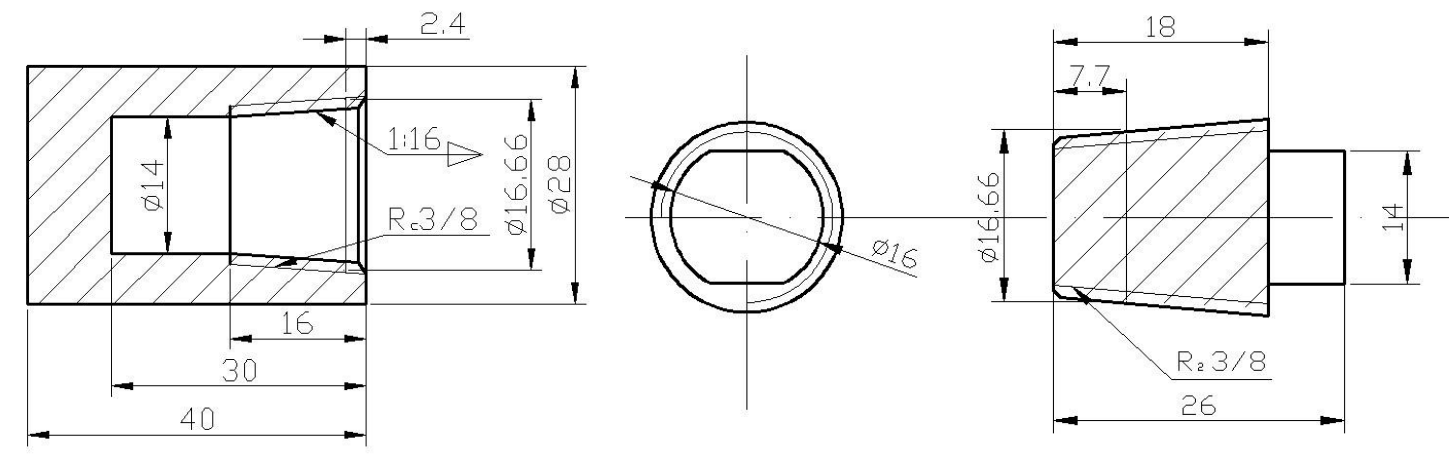

Fig.1 The diagram of the barrel-shaped cylinder and the screw plug

\section{Results and Discussions}

There are at least three different microstructures seen on the metallograph marked by $a, \beta$ and $\gamma$ (see Fig.2) or the backscattered electron image marked by $\mathrm{Ai}, \mathrm{Bi}$ and $\mathrm{Ci}$ (see Fig.3, Fig.4 and Fig.5) in the sample $1(1223 \mathrm{~K}, 50 \mathrm{~h})$, the sample $2(1273 \mathrm{~K}, 50 \mathrm{~h})$ and the sample $3(1323 \mathrm{~K}, 50 \mathrm{~h})$ respectively. The compounds marked by $A_{1}$ and $A_{2}$ show in Platinum grey on the backscattered electron image and in deep gray marked by $a$ on the metallograph. The phases labeled by $C_{l}$ and $C_{2}$ show in ash grey on the backscattered electron image and in gray marked by $\gamma$ on the metallograph. The microstructures indicated by $B_{1}$ and $B_{2}$ show in dark gray on the backscattered electron image and in light gray indicated by $\beta$ on the metallograph.

The main chemical compositions on various microstructures determined by means of electron microprobe are shown in table 1 . The X-ray diffraction pattern of the sample $1(1223 \mathrm{~K}, 50 \mathrm{~h})$ is shown in Fig.6. 
The compounds marked by $A_{1}, A_{2}, A_{3}$ and $A_{4}$ shown in Platinum grey are mainly composed by cerium and arsenic with an atomic ratio approximately 1:1 (see Fig.3, Fig.4, Fig.5 and table.1), based on the results determined by X-ray diffraction and the Cerium Arsenic system diagram (see Fig.6) ${ }^{[3-5]}$, this phase has a CeAs crystal structure.

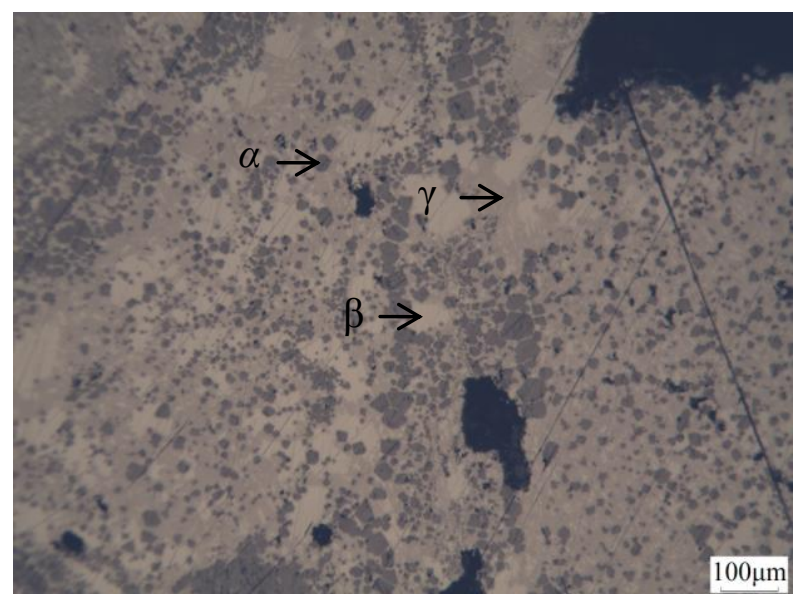

Fig.2 Metallograph of the central area of the sample $1(1223 \mathrm{~K}, 50 \mathrm{~h})$

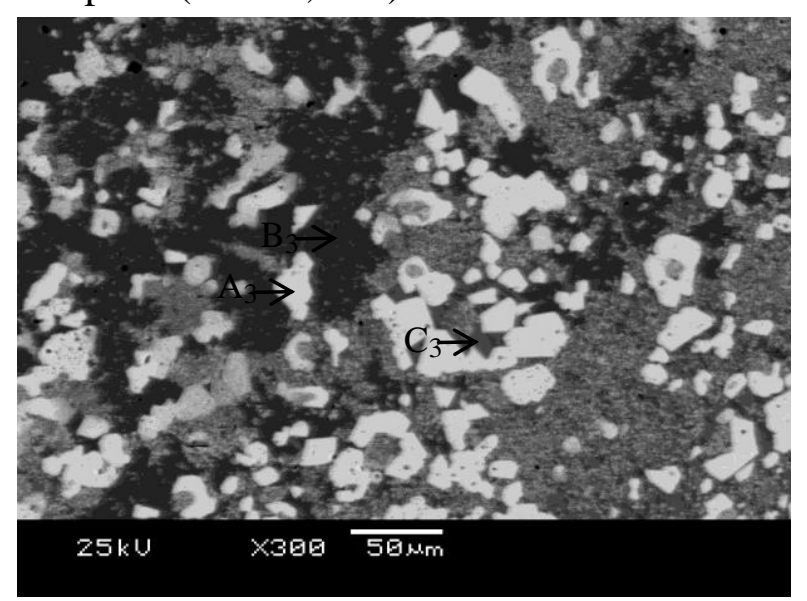

Fig.4 Backscattered electron image of the central area of the sample $2(1273 \mathrm{~K}, 50 \mathrm{~h})$

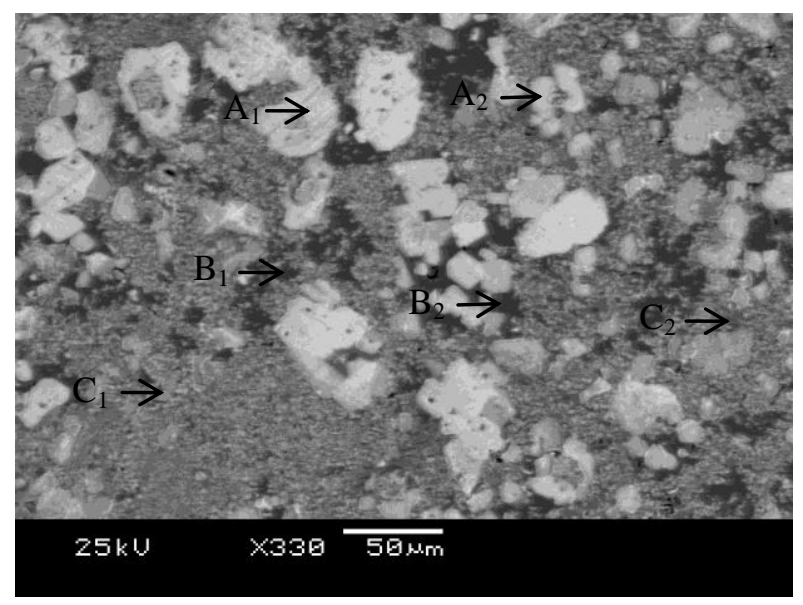

Fig.3 Backscattered electron image of the central area of the sample1 $(1223 \mathrm{~K}, 50 \mathrm{~h})$

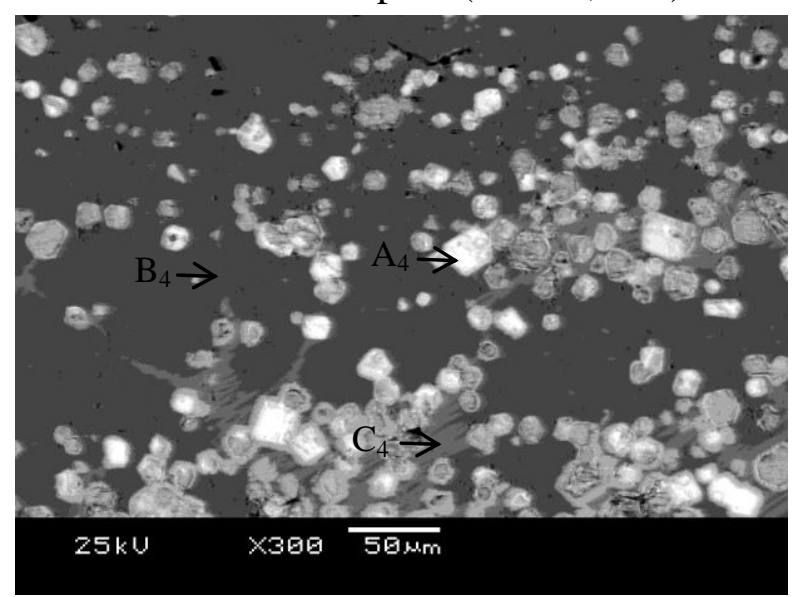

Fig.5 Backscattered electron image of the central area of the sample $3(1323 \mathrm{~K}, 50 \mathrm{~h})$

Table.1 Atomic ratio of element for different microstructure analyzed by electron probe (At \%)

\begin{tabular}{ccccccccccccc} 
area & Ce & Fe & As & area & Ce & Fe & As & area & Ce & Fe & As \\
\hline $\mathrm{A}_{1}$ & 43.05 & 3.12 & 53.83 & $\mathrm{~B}_{1}$ & 0.00 & 90.94 & 9.06 & $\mathrm{C}_{1}$ & 10.86 & 50.54 & 38.60 \\
$\mathrm{~A}_{2}$ & 48.40 & 1.90 & 49.71 & $\mathrm{~B}_{2}$ & 0.12 & 90.29 & 9.59 & $\mathrm{C}_{2}$ & 10.83 & 50.81 & 38.36 \\
$\mathrm{~A}_{3}$ & 42.32 & 3.57 & 54.11 & $\mathrm{~B}_{3}$ & 0.25 & 90.91 & 8.84 & $\mathrm{C}_{3}$ & 10.73 & 50.43 & 38.85 \\
$\mathrm{~A}_{4}$ & 48.45 & 2.36 & 49.19 & $\mathrm{~B}_{4}$ & 0.17 & 90.53 & 9.29 & $\mathrm{C}_{4}$ & 10.82 & 50.56 & 38.62 \\
\hline
\end{tabular}


The phases indicated by $B_{1}$ and $B_{2}$ on Fig.3, by $B_{3}$ on Fig.4, and by $B_{4}$ on Fig.5 shown in dark grey are mainly composed by Iron and Arsenic besides a little amount of Cerium (see table.1). Based on both the phase diagram of Fe-As system and the results determined by X-ray diffraction (see fig.6), the content of arsenic at the area indicated by $B_{1}, B_{2}, B_{3}$ and $B_{4}$ is bigger than the bigest saturated solubility of arsenic in ferrite of iron $(9 \% \mathrm{As} \text {, at } 1113 \mathrm{~K})^{[4]}$, it can be seen that the compound $\mathrm{Fe}_{2} \mathrm{As}$ may be precent at $1223 \mathrm{~K}$; moreover, the compound $\mathrm{Fe}_{2} \mathrm{As}$ will be precipitated from ferrite with the temperature decreasing. Therefore, the microstructure indicated by $B_{1}, B_{2}, B_{3}$ and $B_{4}$ should be a mixture composed by ferrite and a certain amount of $\mathrm{Fe}_{2} \mathrm{As}$. Based on the area size shown in dark gray on the backscattered electron image, there are the most ferrite mixture in the the sample 3, and the least in the the sample 1 (see Fig.3, Fig.4 and Fig.5). It is evident that the amount of the ferrite and $\mathrm{Fe}_{2} \mathrm{As}$ mixture increases with the temperature raising between $1223 \mathrm{~K}$ and $1323 \mathrm{~K}$.

The phases labeled by $C_{1}$ and $C_{2}$ on Fig.3, by $C_{3}$ on Fig.4, and by $C_{4}$ on Fig. 5 shown in ash gray are mainly composed by iron, arsenic and cerium (see table.1). There are small differences among the molar ratios of $\mathrm{Ce}, \mathrm{Fe}$ and As. Comparing with the ternary arsenide $\mathrm{Ce}_{12} \mathrm{Fe}_{57.5} \mathrm{As}_{41}{ }^{[7,8]}$, it can be written as $\mathrm{Ce}_{11.54} \mathrm{Fe}_{53.68} \mathrm{As}_{41}, \mathrm{Ce}_{11.58} \mathrm{Fe}_{54.31} \mathrm{As}_{41}, \mathrm{Ce}_{11.32} \mathrm{Fe}_{53.22} \mathrm{As}_{41}$ and $\mathrm{Ce}_{11.49} \mathrm{Fe}_{53.68} \mathrm{As}_{41}$ respectively by the compositions of the phases labeled by $C_{1}, C_{2}, C_{3}$ and $C_{4}$ according to the stoichiometric (see table.1). Based on the results determined by X-ray diffraction, this phase is the ternary compound $\mathrm{Ce}_{12} \mathrm{Fe}_{57.5} \mathrm{As}_{41}$ (see Fig.6). It can be seen that there are the most compound $\mathrm{Ce}_{12} \mathrm{Fe}_{57.5} \mathrm{As}_{41}$ in the the sample 1, and the least in the sample 3, based on the area size shown in ash gray on the backscattered electron image (see Fig.3, Fig.4 and Fig.5). In other words, it can be thought that the chemical stability of the ternary compound $\mathrm{Ce}_{12} \mathrm{Fe}_{57.5} \mathrm{As}_{41}$ decreased with the temperature raising between $1223 \mathrm{~K}$ and $1323 \mathrm{~K}$.

The ternary compound $\mathrm{Ce}_{12} \mathrm{Fe}_{57.5} \mathrm{As}_{41}$ is the main product basaed on both the highest proportion shown in ash grey on the backscattered electron image and the higher diffraction intensity in the X-ray diffraction pattern of the sample 1 with an atomic ratio of cerium to arsenic 1:3 at $1223 \mathrm{~K}$ keeping 50h (see Fig.3 and Fig.6).

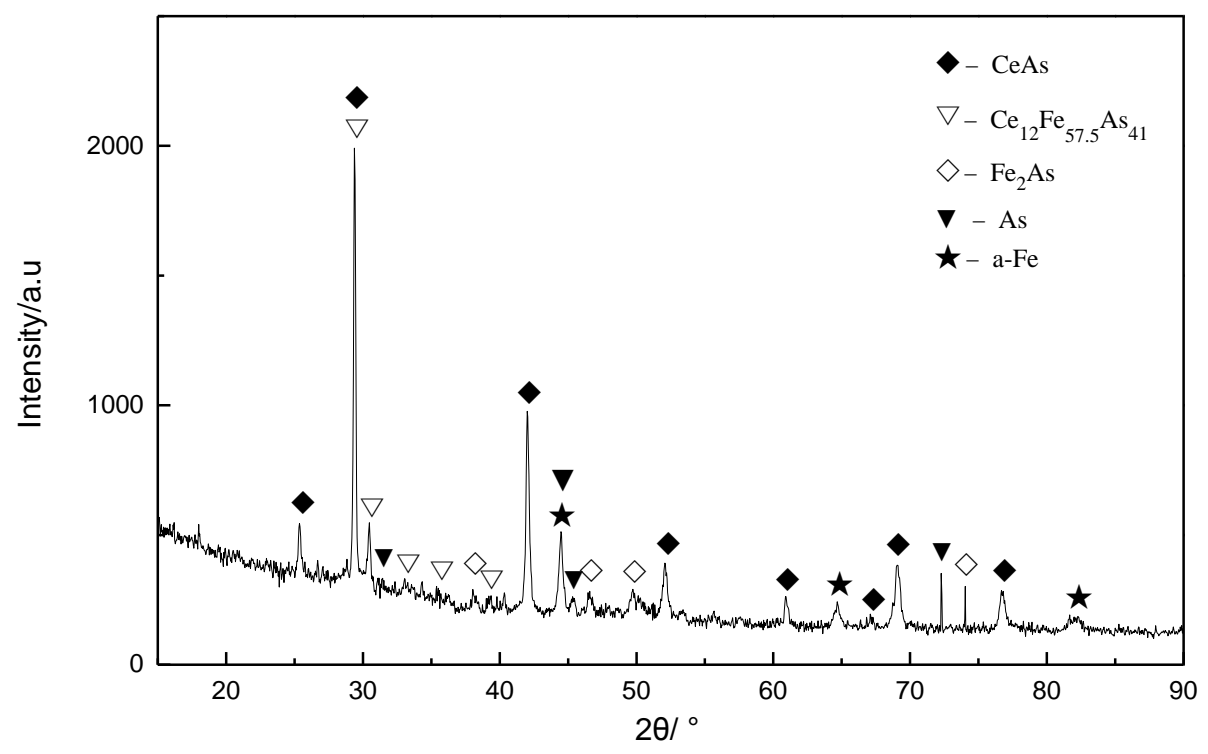

Fig.6 X-ray diffraction pattern of the sample $1(1223 \mathrm{~K}, 50 \mathrm{~h})$ 


\section{Conclusions}

1) The ternary compound $\mathrm{Ce}_{12} \mathrm{Fe}_{57.5} \mathrm{As}_{41}$ is one of the main interaction product at high temperature in Ce-As-Fe system when the atomic ratio of Cerium to Arsenic is 1:3.

2) The ternary compound $\mathrm{Ce}_{12} \mathrm{Fe}_{57.5} \mathrm{As}_{41}$ is the main product of the sample with an atomic ratio of cerium to arsenic 1:3 at $1223 \mathrm{~K}$ keeping $50 \mathrm{~h}$. The chemical stability of the compound $\mathrm{Ce}_{12} \mathrm{Fe}_{57.5} \mathrm{As}_{41}$ decreases with the temperature raising between $1223 \mathrm{~K}$ and $1323 \mathrm{~K}$.

3) The eutectic compound $\mathrm{Fe}_{2} \mathrm{As}$ can be precipitated from ferrite in which there is a high content Arsenic dissolved at high temperature with the temperature decreasing. The amount of the ferrite and $\mathrm{Fe}_{2} \mathrm{As}$ mixture increases with the temperature raising between $1223 \mathrm{~K}$ and $1323 \mathrm{~K}$.

\section{Acknowledgment}

The authors gratefully acknowledge the financial support provided by National Natural Science Foundation of China (50964002) and Graduate innovation fund of Guizhou University (Graduate student of Science and engineering 2015006)

\section{References}

[1] W. F. Gale\&T. C. Totemeir. Smithells Metals Reference Book[M]. Boston: Butterworth-Heinemann, 2004: 497.

[2] Yin Guojin. The Distribution of Arsenic in Steel [J]. Iron \& Steel, 1981, 16(2): 20-28 (in Chinese).

[3] K.A. Gschneidner, Jr. and F.W. Calderwood. The As-Ce (Arsenic-Cerium) System [J]. Bulletin of Alloy Phase Diagrams. 1986, 7(3): 276-277.

[4] V. Babizhets'ky, C. Le Sénéchal, J. Bauer. Interaction of Lanthanum or Cerium with Nickel and Arsenic Phase Diagrams and Structural Chemistry [J]. Journal of Alloys and Compounds. 1999, 287: 174-180

[5] Riccardo Ferro, Gabriella Borzone, Nadia Parodi. Comments on the Formation Thermodynamics of Selected Groups of Rare Earth Compounds [J]. Journal of Alloys and Compounds, 2001, 321: 248-260

[6] Li Daizhong, Gao Shuqin and Zhang Liehuo. Properties of Ce-Fe Intermetallic Compound in Steel [J]. Journal of the Chinese Rare Earth Society, 1985, 3(2):71-72 (in Chinese).

[7] Stanislav S. Stoyko, Peter E. R. Blanchard, and Arthur Mar. Ternary Rare-Earth Iron Arsenides RE12Fe57.5As41 (RE = La, Ce) [J]. Inorganic Chemistry, 2010, 49: 2325-2333.

[8] Jinzhu Zhang, Shengtao Dou. Study on Interaction between Cerium and Arsenic. [J]. Advanced Materials Research, 2011, 194: 1231-1234. 